\title{
Growth of High-quality $\mathrm{Yb}^{3+}$-doped $\mathrm{Y}_{3} \mathrm{Al}_{5} \mathrm{O}_{12}$ Single Crystal Fiber by Laser Heated Pedestal Growth Method
}

\author{
DAI Yun ${ }^{1}$, ZHANG Zhonghan ${ }^{1}$, SU Liangbi ${ }^{1}$, LI Jin ${ }^{2}$, LONG Yong ${ }^{2}$, DING Yuchong ${ }^{2}$, WU Anhua ${ }^{1}$ \\ (1. Key Laboratory of Transparent Optical Functional Inorganic Materials, Shanghai Institute of Ceramics, Chinese Academy of \\ Sciences, Shanghai 201899, China; 2. No.26 Research Institute of China Electronics Technology Group Corporation, Chongqing \\ 400060, China)
}

\begin{abstract}
Single-crystal fiber (SCF) is a fiber-shaped monocrystalline material, which is an important tendency for the development of low-dimensional functional crystals. Combining the excellent optical properties of bulk crystals and the high-efficient thermal dissipation as well as the high beam quality of optical fibers, SCFs are believed to solve the bottlenecks of conventional laser fibers such as unfavorable non-linear effects and poor thermal conductivities, can thus achieve higher laser peak powers and pulse energy. Here, we describe the results of synthesis and characterization of two $\mathrm{Yb}^{3+}$-doped $\mathrm{Y}_{3} \mathrm{Al}_{5} \mathrm{O}_{12}$ (Yb:YAG) SCFs $(\Phi 0.2 \mathrm{~mm} \times 710 \mathrm{~mm})$, which were grown by a selfdeveloped laser-heated pedestal growth (LHPG) apparatus. The prepared SCFs possess a length-to-diameter ratio greater than 3500, a diameter fluctuation less than 5\%, and show high flexibility for bending. The analysis of X-ray rocking curve indicates that the crystallinity of the grown SCF is improved compared with that of the source rod. The EDS line scan shows that the $\mathrm{Yb}^{3+}$ ions are uniformly distributed along the axial direction. Results of these characterizations of SCFs indicate that SCFs maintains excellent crystallinity and high optical homogeneity, showing promising candidate for high-power laser applications.
\end{abstract}

Key words: laser-heated pedestal growth (LHPG); Yb:YAG SCFs; laser crystal

Single crystal fibers are crystals with a fibrous shape. They combine the advantages of bulk crystals (high thermal conductivity, high laser damage threshold, wide light transmission) and glass fibers ${ }^{[1-7]}$ (large specific surface area, high laser conversion efficiency). Theoretical analysis proves that the theoretical single-mode output limit of YAG SCF is 50 times more than that of silica glass fiber, thus YAG based SCFs are a promising candidates for the development of next generation high power lasers ${ }^{[8-10]}$.

During the past years, Yb:YAG SCFs have been extensively investigated for use in high power laser systems due to simple energy level structure of $\mathrm{Yb}^{3+}$ ion, high quantum and slope efficiencies and other excellent physical and chemical properties ${ }^{[11]}$. Yb:YAG crystals are considered one of the most promising fiber materials for lasers in $1 \mu \mathrm{m}$ region ${ }^{[12-14]}$. The two main growth methods of SCFs are Micro-pulling Down( $\mu$-PD) technique and Laser Heated Pedestal Growth (LHPG) technique. At present, the $\mu$-PD method may be used to grow SCFs with diameter greater than $0.5 \mathrm{~mm}^{[15]}$. However, in order to fully take advantage of the large specific surface area of SCFs, Yb:YAG SCFs of larger length-to-diameter ratio and higher shape homogeneity are necessary. Under the circumstance, LHPG method exhibits its advantage of growing SCFs of small diameter, because crucibles are not needed during the growth process and the dimensions of the SCFs are not limited by the shape of crucibles. In this paper, we present the results of our studies on asgrown high-aspect ratio Yb:YAG SCFs with a diameter of $0.2 \mathrm{~mm}$ and a length of $710 \mathrm{~mm}$ that were grown using a self-developed laser-heated base SCF furnace.

\section{Experimental}

\subsection{Growth of SCFs}

The schematic diagram of the LHPG technique is shown

Received date: 2020-08-19; Revised date: 2020-09-29; Published online: 2020-12-01

Foundation item: Instrument Developing Project of the Chinese Academy of Sciences (YJKYYQ20170019); International Partnership Program of Chinese Academy of Sciences (121631KYSB20180045); National Natural Science Foundation of China (51872309, U1832106)

Biography: DAI Yun (1994-), male, Master candidate. E-mail: daiyuncugb@163.com

戴 云(1994-), 男, 硕士研究生. E-mail: daiyuncugb@163.com

Corresponding author: WU Anhua, professor. E-mail: wuanhua@mail.sic.ac.cn 武安华, 研究员. E-mail: wuanhua@mail.sic.ac.cn 
in Fig. 1. For the first pulling we used a $\Phi 2 \mathrm{~mm} \times 100 \mathrm{~mm}$ rods that were cut out of bulk Yb:YAG crystals (Yb concentration were $1 \mathrm{at} \%$ or $2 \mathrm{at} \%$ ). The diameter of the SCF can be controlled by adjustment of the ratio of the seed crystal pulling speed to the source rod feeding speed. Usually this ratio is set to $1 / 2-1 / 3^{[16]}$. The diameter of the first grown fibers were $0.7 \mathrm{~mm}$. Subsequently, the firstgrown SCFs were used as a source rod and seed crystal for the second growth. The second-grown SCFs with diameter of $0.2 \mathrm{~mm}$ were grown by adjusting the appropriate pull to feed ratio. The growth rate can reach up to $200-300 \mathrm{~mm} / \mathrm{h}$.

After two times of growth, we obtained 1at $\%$ Yb:YAG and $2 \mathrm{at} \% \mathrm{Yb}: Y A G$ SCFs with a diameter of $0.2 \mathrm{~mm}$ and a length of $710 \mathrm{~mm}$ (the length-diameter ratio is greater than 3500:1). Photographs of obtained SCFs are shown in Fig. 2 and Fig. 3.

\subsection{Characterizations}

The axial distribution of $\mathrm{Yb}^{3+}$ ions was characterized by Energy Dispersive Spectrometer (EDS). The X-ray rocking curves of the SCFs were measured by $18 \mathrm{~kW}$ target-rotating X-ray diffractometer (D/Max $2550 \mathrm{~V})$ to characterize their crystal quality. Laue diffraction patterns

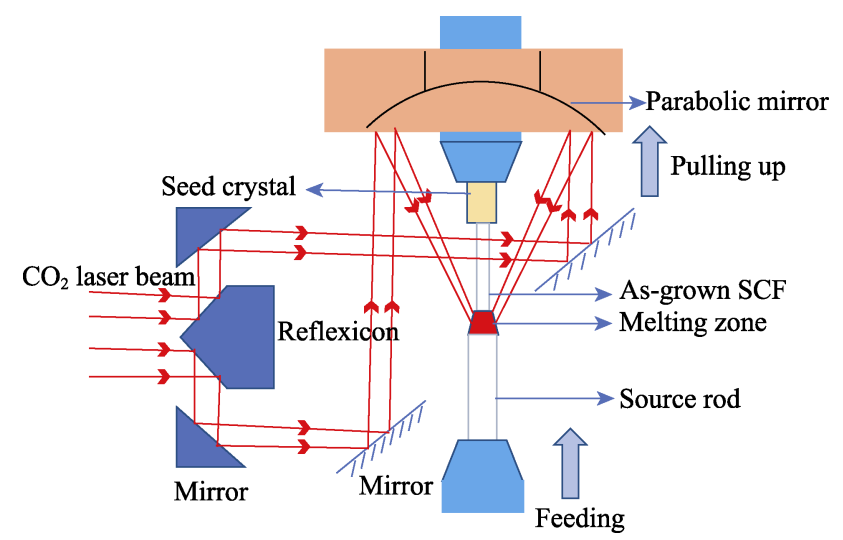

Fig. 1 Schematic diagram of the LHPG technique

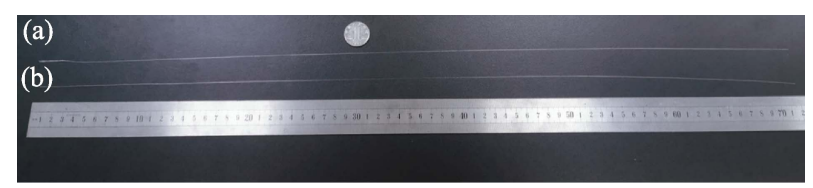

Fig. 2 Pictures of as-grown Yb:YAG SCFs

(a) $1 \mathrm{at} \%$ Yb:YAG; (b) $2 \mathrm{at} \% \mathrm{Yb}: Y A G$
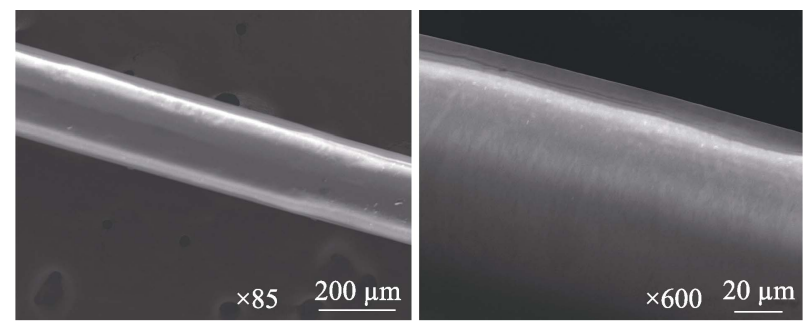

Fig. 3 Different magnification SEM microphotographs of the $1 \mathrm{at} \% \mathrm{Yb}:$ YAG SCF were obtained using a real-time back-reflection Laue camera system (Multiwire MWL 120 with Northstar software).

\section{Results and discussion}

The stability of optical system is the prerequisite for the growth of SCF of high quality. If the power of the $\mathrm{CO}_{2}$ laser in the optical heating system fluctuates during the growth of the fiber, it leads to the fluctuation of fiber diameter. When the change is too large, it results in solidification of the melting zone or the seed crystal detaches from the melting zone and stops growing. Therefore, the LHPG SCF furnace needs a $\mathrm{CO}_{2}$ laser with relatively stable power output. In addition, the adjustment of the optical path also has great influence on the crystal quality. If the laser beam fails to achieve symmetrical focus heating, as shown in Fig. 1, it results in asymmetric melting zone, as shown in Fig. 4. The asymmetric melt zone causes instability of the fiber diameter or even leads to the stop of the growth. In the process of designing the LHPG SCF furnace, the dimension deviation of each part of the optical system from the theory is not more than $0.01 \%$. We also added a visible laser system parallel to the side of the $\mathrm{CO}_{2}$ laser with the distance of $2 \mathrm{~cm}$. The system allows to adjust the position of each component while observing the heating ring change dynamically. Using trial and error approach, taking the quality of the grown fiber feedback parameter, the best focusing position is found, which laid a foundation for the growth of high-quality fibers.

In the process of growth, it is found that the ratio of pulling speed, feeding speed and laser power had a great influence on the melting zone, thus affecting the fiber quality. Let the laser power in the growth process be $P$, the heat dissipated from the molten zone to the source rod direction be $Q_{1}$, and the heat dissipated from the molten zone to the seed crystal direction be $Q_{2}$. The heat dissipation of the molten zone itself is contained in the $\eta$ factor. According to the reference ${ }^{[17]}$, the total energy conservation equation is as follows:
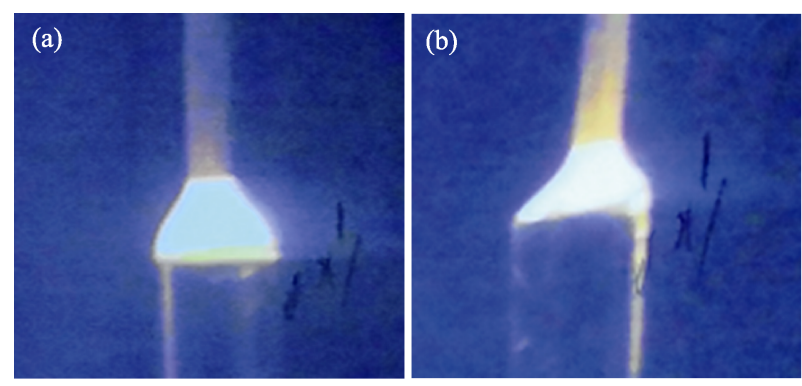

Fig. 4 Photographs of melt zone in the process of fiber growth (a) Symmetrical zone configuration; (b) Asymmetric zone configuration 


$$
\eta P=Q_{1}+\Delta H_{\mathrm{f}} \frac{\pi D^{2}}{4} V_{\mathrm{S}}+Q_{2}-\Delta H_{\mathrm{f}} \frac{\pi d^{2}}{4} V_{\mathrm{f}}
$$

$\Delta H_{\mathrm{f}}$ is the melting heat of the source rod; $D$ and $V_{\mathrm{S}}$ are the diameter and feeding speed of the source rod respectively; $d$ and $V_{\mathrm{f}}$ are the diameter and pulling speed of the seed crystal. When the growth process is stable, $\Delta H_{\mathrm{f}} \frac{\pi D^{2}}{4} V_{\mathrm{S}}=\Delta H_{\mathrm{f}} \frac{\pi d^{2}}{4} V_{\mathrm{f}}$. Assuming that $P$ changes slightly under $V_{\mathrm{S}}$, it can be approximated that $Q_{1}, Q_{2}$ and $\eta$ do not change, while $V_{\mathrm{s}}, V_{\mathrm{f}}$ and $D$ are constant. Therefore, $d$ changes with the change of $P$, thus affecting the melting zone, and the melting zone responds quickly to the laser power. But the response of the melting zone to the pushpull ratio is slightly delayed. The corresponding process is shown in Fig. 5. The seed crystal pulling speed of 300 $\mathrm{mm} / \mathrm{h}$ and the source rod feed speed of $40 \mathrm{~mm} / \mathrm{h}$ are chosen for fiber growth in the second growth.

On continuous SCFs with sufficient length, no macroscopic defects were observed. We record the fiber diameter by taking a measurement every $20 \mathrm{~mm}$. Results are shown in Fig. 6(a). The diameter change is calculated by a formula $A=\Delta d / \bar{d}, \Delta d=|d-\bar{d}|$. Where $d$ is the diameter of each measurement point on SCF, and $\bar{d}$ is the average diameter value. The diameter fluctuations are shown in Fig. 6(b). It can be seen that the diameter fluctuation is less than $5 \%$. Better diameter uniformity is beneficial for the fabrication of cladding and related devices ${ }^{[16]}$. The growth quality of the fiber was characterized by measuring the rocking curve of $\mathrm{Yb}$ :YAG SCF (111) crystal plane Fig. 7. It can be seen that the rocking curve presents a symmetrical shape without splitting. The full width at half maximum (FWHM) of the fitted peaks for each sample are gathered in Table 1. The FWHM values for SCF are lower than that of the source rods, indicating that the as-grown crystal fibers

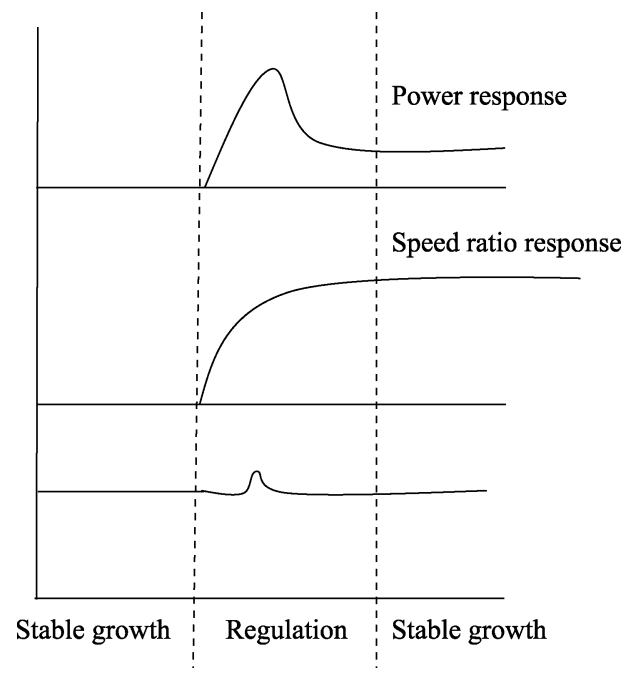

Fig. 5 Process diagram for controlling the diameter of a SCF have higher quality than source rods. It also can be clearly seen from Fig. 8 that the characteristic Laue XRD patterns of Yb:YAG SCFs with two concentrations are uniform, clear and bright.

The Energy Dispersive Spectrometer (EDS) was used to check the axial distribution of $\mathrm{Yb}^{3+}$ ions along the SCF by line scanning. The variation of $\mathrm{Yb}^{3+}$ concentration along the axial direction is shown in Fig. 9. The results
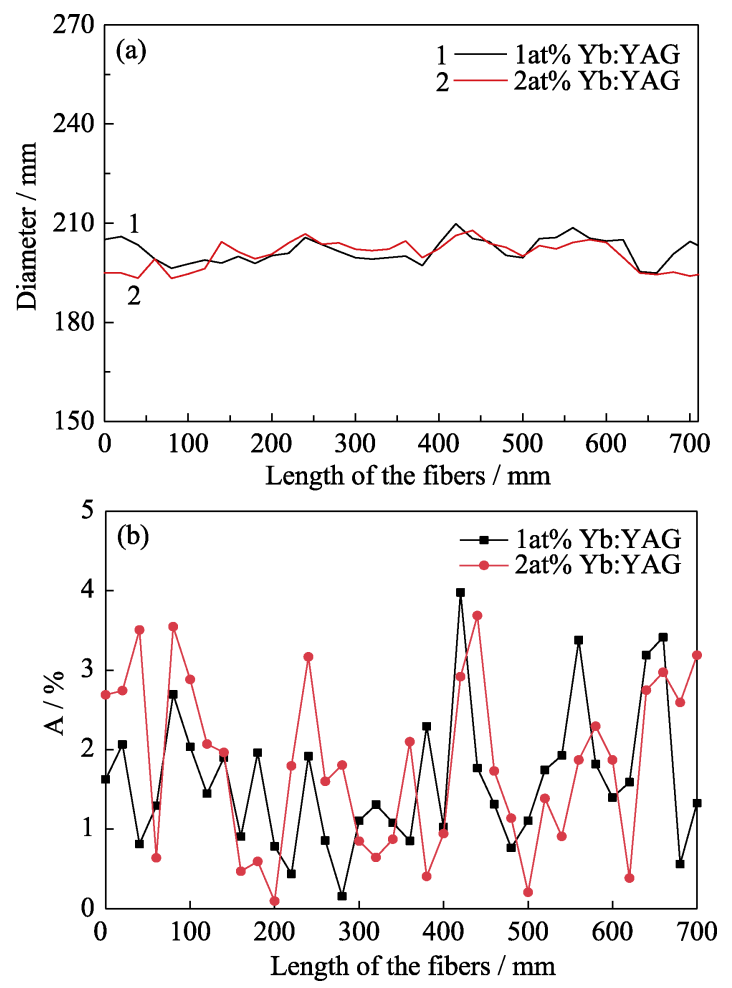

Fig. 6 Variation of diameter along the fibers

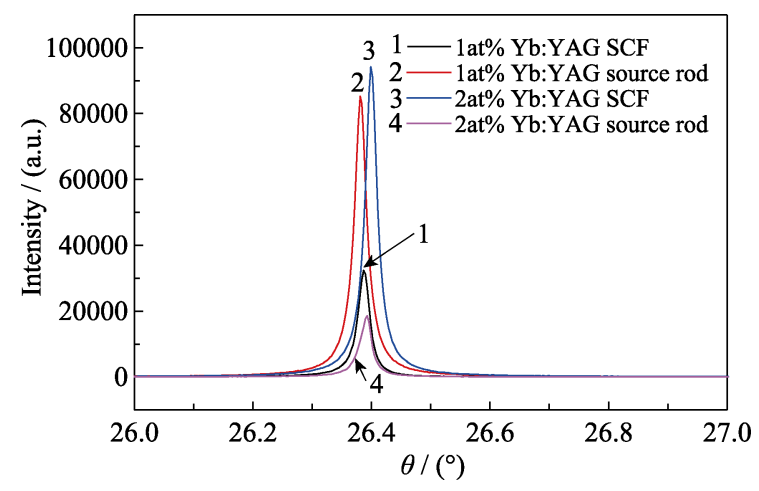

Fig. 7 X-ray rocking curves of the (111) crystal plane of the $\mathrm{Yb}$ :YAG SCFs and source rod

Table 1 FWHM of Yb:YAG SCFs and source rods

\begin{tabular}{ccc}
\hline No. & Sample & FWHM/(") \\
\hline 1 & 1at\% Yb:YAG SCF & 111.6 \\
2 & 1at\% Yb:YAG source rod & 129.6 \\
3 & 2at\% Yb:YAG SCF & 111.6 \\
4 & 2at\% Yb:YAG source rod & 126.0 \\
\hline
\end{tabular}




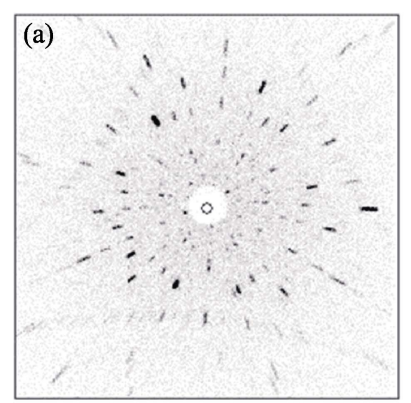

Cutoff $=10 ;$ Number of points 0

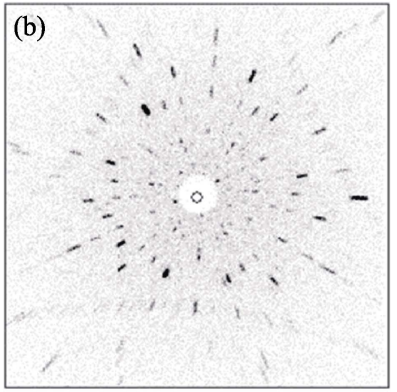

Cutoff $=10$; Number of points 0
Fig. 8 Characteristic Laue back-reflection patterns of Yb:YAG (a) $1 \mathrm{at} \% \mathrm{Yb}: \mathrm{YAG}$; (b) $2 \mathrm{at} \% \mathrm{Yb}: \mathrm{YAG}$

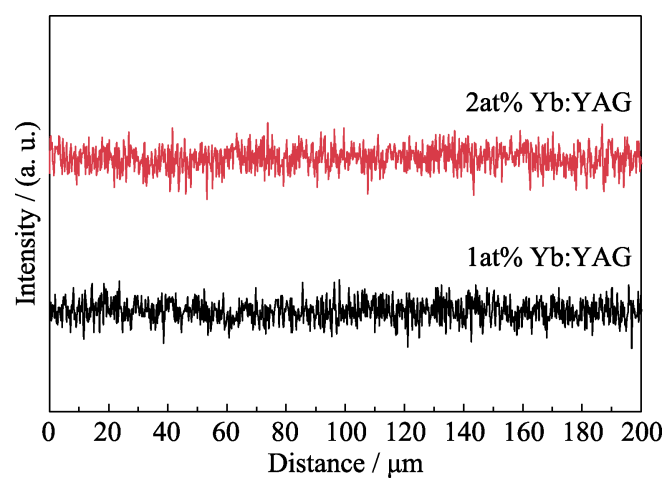

Fig. 9 Distribution of $\mathrm{Yb}^{3+}$ ions along the axial direction in grown SCFs

show that $\mathrm{Yb}^{3+}$ ions are relatively evenly distributed along axial direction. The effective ionic radius of $\mathrm{Yb}^{3+}$ ion is similar to that of $\mathrm{Y}^{3+}$ ion, so $\mathrm{Yb}^{3+}$ ions can easily enter $\mathrm{Y}^{3+}$ sites in YAG crystals ${ }^{[18]}$. On the other hand, the molten zone formed in the process of LHPG growth is small, and the rapid melting and solidification are influential for the inhibition of segregation. The uniform distribution of $\mathrm{Yb}^{3+}$ ions along material is one of the key factors for single-mode lasers materials.

Various YAG SCFs grown by LHPG method were already reported (as shown in Table 2). It can be seen from the table that the fiber quality is comprehensively characterized in this study. It also has some advantages in

Table 2 YAG SCF grown by LHPG method

\begin{tabular}{cccccc}
\hline Type & $\begin{array}{c}\text { Diameter } \\
/ \mathrm{mm}\end{array}$ & $\begin{array}{c}\text { Length } \\
/ \mathrm{mm}\end{array}$ & Uniformity & $\begin{array}{c}\text { Concentration } \\
\text { distribution }\end{array}$ & Ref. \\
\hline Yb:YAG & 0.6 & 150 & $<2 \%$ & $\sqrt{ } \%$ & {$[16]$} \\
Yb:YAG & 0.8 & Centimeters & - & - & {$[15]$} \\
Yb:Ho:YAG & 0.45 & 124 & - & - & {$[8]$} \\
Tm/Yb:YAG & 0.8 & 40 & - & $\checkmark$ & {$[19]$} \\
Ho:YAG & 0.32 & 280 & - & - & {$[20]$} \\
Ho:YAG & 0.24 & 118 & - & - & {$[21]$} \\
Nd:YAG & $0.6-1.2$ & 300 & - & - & {$[22]$} \\
Nd:YAG & 1 & 42 & - & - & {$[23]$} \\
Nd:YAG & 0.6 & 25 & - & - & {$[24]$} \\
\hline
\end{tabular}

fiber quality and fiber length and diameter.

\section{Conclusions}

High quality $\mathrm{Yb}$ :YAG SCFs with a diameter of $0.2 \mathrm{~mm}$ and a length of $710 \mathrm{~mm}$ were successfully grown by LHPG. The fiber diameter fluctuation is less than $5 \%$ and $\mathrm{Yb}^{3+}$ ions are homogeneously distributed along the fiber axis. The X-ray rocking curve indicates the as-grown crystal fibers are of high quality. The growth of high quality SCFs lays the foundation for the further experiments with the fiber cladding and construction of the fiber laser.

\section{References:}

[1] SOLEIMANI N, POTING B, GEBREMICHAEL E, et al. Coilable single crystals fibers of doped-YAG for high power laser applications. Journal of Crystal Growth, 2014, 393: 18-22.

[2] HARRINGTON J. Single-crystal fiber optics: a review. Proceedings of SPIE, 2014, 8959: 895902.

[3] DELEN X, AUBOURG A, DEVRA L, et al. Single crystal fiber for laser sources. Proceedings of SPIE, 2015, 9324: 934202.

[4] DAWSON J W, MESSERLY M J, BEACH R J, et al. Analysis of the scalability of diffraction-limited fiber lasers and amplifiers to high average power. Optics Express, 2008, 16(17): 13240-13266.

[5] BRIDGES T J, HASIAK J S, STRNAD A R. Single-crystal AgBr infrared optical fibers. Optics Letters, 1980, 5(3): 85-86.

[6] RIBERIRO R M, FIASCA A B A, SANTOS A M. Optical activity measurements in the photorefractive $\mathrm{Bi}_{12} \mathrm{TiO}_{20}$ single crystal fibers. Optical Material, 1998, 10: 201-205.

[7] LEBBOU K. Single crystals fiber technology design. Where we are today? Optical Material, 2017, 63: 13-18.

[8] YANG Y L, YE L H, BAO R J. Growth and characterization of Yb:Ho:YAG single crystal fiber. Infrared Physics \& Technology 2018, 91: 85-89.

[9] PARTHASARATHY T A, HAY R S, FAIR G. Predicted performance limits of yttrium aluminum garnet fiber lasers. Optical Engineering, 2010, 49(9): 094302.

[10] NIE C D, BERA S, HARRINGTON J A. Growth of single-crystal YAG fiber optics. Optics Express, 2016, 24(14): 15522-15527.

[11] MU X D, MEISSNER S, MEISSNER H. Laser diode pumped high efficiency Yb:YAG crystalline fiber waveguide lasers. Proceedings of SPIE, 2015, 9342: 934205.

[12] CLARKSON W A, KOCH R, HANNA D C. Room-temperature diode-pumped Yb:YAG laser at $946 \mathrm{~nm}$. Optics Letters, 1999, 21(10): 737-739.

[13] DELEN X, ZAOUTER Y, MARTIAL I, et al. Yb:YAG single crystal fiber power amplifier for femtosecond sources. Optics Letters, 2013, 38(2): 109-111.

[14] CHANI V. I, YOSIKAWA A, KUWANO Y, et al. Preparation and characterization of $\mathrm{Yb}: \mathrm{Y}_{3} \mathrm{Al}_{5} \mathrm{O}_{12}$ fiber crystals. Materials Research Bulletin, 2000, 35: 1615-1624.

[15] YOSHIKAWA A, BOULON G, LAVERSENNE L, et al. Growth and spectroscopic analysis of $\mathrm{Yb}^{3+}$-doped $\mathrm{Y}_{3} \mathrm{Al}_{5} \mathrm{O}_{12}$ fiber single crystals. Journal of Applied Physics, 2003, 94(9): 5479-5487.

[16] WANG T, ZHANG J, ZHANG N, et at. The characteristics of highquality Yb:YAG single crystal fibers grown by a LHPG method and the effects of their discoloration. RSC Advances, 2019, 9: 22567-22575. 
[17] CRSLAW H S, JAEGER J C. Conduction of Heat in Solids. New York: Oxford Univcrsity Press, 1959: 387.

[18] REINBERG A R, RISEHERG L A, BROWN R M, et al. GaAs: Si LED pumped Yb-doped YAG laser. Applied Physics Letters, 1971, 19(1): 11-13.

[19] YU L, YA L, BAO R, et al. Sensitivity-enhanced $\mathrm{Tm}^{3+} / \mathrm{Yb}^{3+}$ codoped YAG single crystal optical fiber thermometry based on upconversion emissions. Optics Communications, 2018, 410: 632-636.

[20] LI Y, MILLR K, JOHNSON E G, et al. Lasing characteristics of Ho:YAG single crystal fiber. Optics Express, 2016, 24(9): 9751-9756.
[21] LI Y, ZHANG Z Y, BUCKLEY I, et al. Investigation of the amplification properties of Ho:YAG single crystal fiber. Proceedings of SPIE, 2015, 9342: 934205.

[22] SHEN J W, WU B, SHEN Y H. High power CW laser operation with a Nd:YAG single-crystal fiber grown by LHPG method. Laser Physics, 2009, 19(10): 2031-2034.

[23] TONG L M, ZHU D, LUO Q M. A laser pumped $\mathrm{Nd}^{3+}$-doped YAG fiber-optic thermal tip for laser thermotherapy. Lasers in Surgery and Medicine, 2002, 30: 67-69.

[24] TONG L M, LOU J Y, HONG D F. A fiber-optic thermal source for laser surgery applications. Proceedings of SPIE, 2000, 4224: $135-138$.

\title{
激光加热基座法生长高质量 $\mathbf{Y b}^{3+}$ 掺杂 $\mathbf{Y}_{3} \mathbf{A}_{15} \mathbf{O}_{12}$ 单晶光纤
}

\author{
戴 ${ }^{2}{ }^{1}$, 张中晗 ${ }^{1}$, 苏良碧 ${ }^{1}$, 李 金 $^{2}$, 龙 勇 $^{2}$, 丁雨憧 ${ }^{2}$, 武安华 ${ }^{1}$
}

(1. 中国科学院 上海硅酸盐研究所, 中国科学院透明光功能无机材料重点实验室, 上海 201899; 2. 中国电子科技 集团公司 第二十六研究所, 重庆 400060)

摘 要: 单晶光纤即具有光纤形态的单晶材料, 是功能晶体材料一维化发展的重要体现。单晶光纤兼具单晶材料优 异的光学性能和激光光纤散热效率高、光束质量高等特点, 有望解决传统玻璃材质激光光纤非线性效应强、热导率 低等瓶颈问题, 实现激光峰值功率、脉冲能量等性能的突破。本工作采用自主研制的激光加热基座(Laser-heated Pedestal Growth, LHPG)单晶光纤炉制备了两组 $\Phi 0.2 \mathrm{~mm} \times 710 \mathrm{~mm}$ 的 $\mathrm{Yb}^{3+}$ 掺杂 $\mathrm{Y}_{3} \mathrm{Al}_{5} \mathrm{O}_{12}(\mathrm{Yb}: \mathrm{YAG}$ )单晶光纤, 并对其 进行了表征。制备的单晶光纤长径比大于 3500 , 直径波动小于 $5 \%$, 且表现出一定的柔韧性; $X$ 射线摇摆曲线测试 结果显示 $\mathrm{Yb}: \mathrm{YAG}$ 单晶光纤的结晶质量与所用源棒相比有所提升; EDS 线扫描结果证明单晶光纤中的 $\mathrm{Yb}^{3+}$ 沿轴向 呈现均匀分布。实验结果表明: 准一维化的单晶光纤具有良好的结晶质量与光学均匀性, 有望成为一种性能优异的 高功率激光增益材料。

关 键 词: 激光加热基座法(LHPG); Yb:YAG 单晶光纤; 激光晶体

中图分类号: TQ174 文献标志码: A 